\title{
Research on Game Strategy between Node Enterprises in Thermal Coal Supply Network
}

\author{
Jikai Huang \\ Beijing Jiaotong University, Haidian District, Beijing, China
}

\begin{abstract}
The main purpose of this paper is to study the relationship between the costs and profits of coal enterprises and coal-fired power plants based on the game strategy under different factors. By analyzing the status quo of coal supply nodes, the article analyzes the game of coal supply enterprises in the state of cooperation and non-cooperation, and analyzes the quantum game of coal enterprises and coal-fired power plants in two cases. The first is that one adopts the traditional game strategy and the other uses the quantum game strategy. The second is both of them using quantum game strategy. Finally, it is concluded that the increase of electricity price, the reduction of other costs of power enterprises and the reduction of the cost of coal enterprises will lead to the increase of cooperative profits between coal enterprise and coal-fired power plants in the coordination game. Secondly, the decision-making among firms has nothing to do with the Nash equilibrium in the noncooperative game. Thirdly, the enterprises that use the quantum game will earn more profit.
\end{abstract}

Keywords-thermal coal supply; synergistic supply; node enterprise; quantum game

\section{INTRODUCTION}

The issue of thermal coal supply and transportation has played a key role in the balance of electricity industry and coal industry in China. Thermal coal supply companies, transport companies, transit centers and power plants exist competition and cooperation based on cost, electricity price, freight rates. This is a competition on the commercial interests of thermal coal circulation. There are many sufficient game research cases on the thermal power supplying node enterprises. For instance, Younes Z., \& Ilic M. analyzed the supply function model for coal-fired power plant. The author considers that in the shortterm price or supply function competition, the multi-period and static Nash equilibrium models are more realistic than the Cournot model ${ }^{[1]}$. Ferrero R.W., Rivera J.F. and Shahidehpour S.M. analyze the Nash equilibrium of the market by using the non-cooperative game theory in the context of the joint venture and incomplete information. They assume that market participants have incomplete information. The participants only know their own costs, and they do not understand the cost of opponents. Through the non-cooperative game theory to explore the optimal strategy of participants, in order to obtain the electricity price of the market ${ }^{[2]}$. Green R. studied the competition in the electricity market. He pointed out that in a complete competitive market, in order to obtain maximum profits, power generation companies will determine the price according to the marginal cost. At the same time, he constructed the Cournot equilibrium model and the supply function for the electricity market and studied the impact of network constraints on electricity prices in the electricity market ${ }^{[3]}$.

Chinese scholars have realistic research results on the game of supply transaction between steam coal suppliers. For example, Han Fuchun, Tao Weiqiang, and Lu Yingchun use the Cournot model and the Bertrand model respectively to establish corresponding bidding models for coal-fired power plant, and show that Nash equilibrium does exist in an oligopolistic market ${ }^{[4]}$. Yuan Zhiqiang, Jiang Chuanwen and Hou Zhijian (2007) studied the Nash equilibrium of bidding strategies of power suppliers by game theory and optimal power flow (OPF) in complete information conditions [5]. Zhang Yubo, Luo Xianjue and Xue Junyi study the antidemand curve of the known market electricity but unknown the production costs of other power plants in order to obtain the maximum profit in the oligopoly market. The power plant uses a Cournot model with constraints and optimizes the output of the generator set ${ }^{[6]}$. Liao Jiaping introduced the Cournot model. He used game theory to analyze the incomplete information in Nash equilibrium and bidding strategies of power plants under symmetric and asymmetric conditions, and proposed a bidding strategy based on game theory ${ }^{[7]}$.

\section{CURRENT SituAtion OF NODE ENTERPRISES IN COAL SUPPLY NETWORK}

\section{A. Transport Companies}

The node enterprises of Chinese thermal coal supply network are mainly composed of railway transport enterprises, motor transport enterprises, water transport enterprises and coal transit centers.

The rail freight is the main transportation mode for the "western coal transport to the east" in China, in which the thermal coal volume of rail freight accounts for over $70 \%$ of the national thermal coal volume of rail freight. Due to the unbalanced distribution of coal and coal-fired plants, a number of railway routes for coal freight have been built from Northern China to Southern China and from Western China to Eastern China. From 2009 to 2014, about 60\% of China's coal production is transported by railway. In 2015, coal production in China was about 3.75 billion tons (declined 3.2\% compare to last year). The coal transported by railway reached about 2 billion tons (decrease $12.6 \%$ from the last year), and the railway freight volume accounted for $53.3 \%$ is the coal output. Thermal coal freight volume by rail is about 1.38 billion tons, 
accounting for $68.8 \%$ of railway freight volume for coal, and railway transportation for thermal coal accounting for $36.8 \%$ of total railway freight volume ${ }^{[8]}$. Recent years, the number of coal-fired plants has risen sharply, and most of them are far away from the coal producing areas, thus it makes the railway transport insufficient capability for coal freight ${ }^{[9]}$.

Waterways transport play an important role in the transportation of coal. Because of the low cost and large carrying capacity of waterways transport, it is suitable for carry bulk cargo such as coal. The waterways transport of thermal coal including transport by inland river and marine transport in China. Thermal coal transported to coal consumption sites in southeastern of China by waterway transport from the places such as Shandong, Shanxi, Henan, Hebei and Jiangsu province. The coal receiving volume in Shanghai, Jiangsu, Zhejiang, Fujian and Guangdong accounts for $88.5 \%$ of the domestic coal water transport volume [10]. From 2009 to 2012, coal volume of waterway freight accounted for about $15 \%$ of the total volume of waterways freight, but dropped to about $12 \%$ from 2013 to $2015^{[8]}$. In recent years, the rapid development of the port has been driven by the considerable profits and low monopoly of waterway coal transportation. The water transport capacity of Thermal coal has greatly improved, Tianjin Port and Qinhuangdao have maintained a 20\% growth rate of thermal coal freight by waterway.

Motor transport is not suitable for transporting thermal coal over long distances, due to the truckload is less than trains and cargo ship. Due to the high flexibility of motor transport, most of the time it is used as a supplementary transport mode to link up with rail transport and water transport in order to achieve the purpose of transshipment. Due to its high flexibility, motor transport can be an important complement to the coal transport of railways and waterways. In 2015, coal volume of road freight accounted for only $2.63 \%$ of the total volume of road freight, but the coal volume of road freight accounted for $22.13 \%$ of the national coal output ${ }^{[8]}$. However, due to the shortage of railway transport capacity in recent years, the long distance thermal coal transportation by vehicles has gradually increased.

\section{B. Transit Centers}

Nowadays, the main functions of thermal coal transit centers include: coal washing and blending services, reserves and high-volume procurement.

In order to achieve the needs of different coal-fired plants, the coal transit center needs to do coal washing, classify and coal blending. It reduces the costs of coal-fired plants, increases coal utilization and reach environmental requirements.

The transit center effectively relieves the seasonal shortage of coal transportation by storing thermal coal. The reserve of thermal coal ensures the conventional demand of coal-fired power plants in the region. In this process, thermal coal producers, consumer companies and transit companies need to work closely together to achieve integrated inventory management to reduce inventory management costs. Thermal coal transit center for the consumer to provide a reliable supply guarantee, but also be able to ease the power shortage situation.
Through the large-scale operation of the coal transit center, it helps to promote technological innovation, facilitate environmental protection and increase profits. According to historical data, the service cost of blending coal is 5 to 10 RMB per ton, and if the scale of the transit center is 15 million tons per year, and the average charge is $8.5 \mathrm{RMB}$, the annual income will reach 127.5 million RMB per year ${ }^{[11]}$.

\section{GAME ANALYSIS OF COAL SUPPLy NETWORK IN ENTERPRISE COLLABORATION}

In the coal industry and the coal-fired industry, the flow of thermal coal as a link formed a supply and demand chain of "coal enterprises - logistics enterprises - coal-fired power plants - power users." In this supply chain, the game playing between enterprises is based on coal prices. This triggered a long-term tripartite game among coal enterprises, electricity companies and governments as well as the long-term tripartite game between coal enterprises, electricity companies and logistics enterprises ${ }^{[12]}$.

The situation of both sides in the thermal coal supply chain is cooperation and conflict. The purpose of the cooperation between steam coal supply enterprises is to create an interdependent and mutual trust relationship through which all enterprises share information, share risks and make profits together. Enterprises in coal supply chain have the characteristics of competition conflict and cooperation conflict. Because the enterprises in the steam coal supply chain are closely related, the conflict in the coal supply chain has the characteristics of the competition conflict and the cooperation conflict.

The solution to the conflict of thermal coal supply chain mainly includes self-executing agreement model, relational rent maximization and self-enforcing regulation model.

First, set up the basic model. Let the government control the electricity price as $P_{E}$, and the electricity demand as $\mathcal{Q} . V_{E}$ is the unit cost of the coal-fired power plant (excluding the purchasing cost of thermal coal). $P_{c}$ is the coal price. $P_{l}$ is the logistics price produced by unit coal, and $V_{l}$ is the coal unit logistics cost.

Establish the profit function of coal-fired power plant:

$$
\pi_{E}=\left(P_{E}-P_{c}-V_{E}\right) \mathcal{Q}
$$

Coal enterprise profit function:

$$
\pi_{c}=\left(P_{c}-V_{c}\right) Q_{C}
$$

Third-part logistics business profit function:

$$
\pi_{l}=\left(P_{l}-V_{l}\right) \mathcal{Q}_{c}
$$

$V_{c}$ is the unit cost of coal enterprises; $\mathcal{Q}_{C}$ is the sales volume of coal.

The demand function of coal-fired power plant for coal is: 


$$
Q_{C}=c-d P_{c}
$$

Since the demand for coal $\mathcal{Q}_{C}$ is positively correlated with the consumption of electricity $\mathcal{Q}$, it is assumed that:

$$
\mathcal{Q}=\mathrm{k} \mathcal{Q}_{C}, 0<\mathrm{k}<1
$$

To sum up,

$$
\pi_{E}=\left(P_{E}-P_{c}-V_{E}\right) \mathcal{Q}=\mathrm{k}\left(P_{E}-P_{c}-V_{E}\right) Q_{C}
$$

The volume of third-part logistics is accordance to the coaldemand $\mathcal{Q}_{C}$.

In order to facilitate the analysis of the problem, the following assumptions are proposed:

Suppose that there is only one coal-fired power plant and coal enterprise, coal-fired power plant and coal enterprise on the market can be regarded as a combination of all coal-fired power plant and all coal coal-fired power plant respectively.

When the power supply is tight, the coal-fired plants has increased demand for thermal coal. At this moment, the coal enterprises are in a strong position in the coal market with strong bargaining power. The coal enterprises take the initiative first and the coal-fired plants then take actions.

When the power supply surplus, the coal-fired plants has reduced demand for thermal coal. At this time, in the coal market, coal-fired plants stay in a strong position, also the bargaining power is stronger than coal enterprise. The coalfired plants take action first, then the coal enterprise move.

When the electricity supply is tight, the coal enterprises take the initiative. Due to the government regulation, the coal enterprises unable to raise the coal prices, and it only can increase the profits by increasing the coal's output. Therefore, the coal enterprises can only make decisions by increasing the sales volume.

When the power supply surplus, coal-fired power plant have the initiative. Due to the price of electricity in the market should to be publicity online. It makes the cost competitiveness of coal-fired power plants increased. Coalfired power plant should control the purchase price of coal.

Suppose the profit function is known by both sides.

Conduct game analysis when coal enterprises and electricity enterprises collaborate. The first step is to calculate the impact of changes in electricity prices and costs on the profits of cooperative ventures.

Suppose the cooperation between coal-fired power plant and coal enterprises, the total profit is $\pi_{T}^{c}$, then

$$
\pi_{T}^{c}=\mathrm{k}\left(P_{E}-P_{c}-V_{E}\right) Q_{C}+\left(P_{C}-V_{C}\right) Q c+\left(\mathrm{P}_{l}-\mathrm{V}_{l}\right)
$$

The first-order derivative of the total profit function gives the Nash equilibrium as:

$$
\mathrm{P}_{c}^{c}=\frac{(k-1) c+d k\left(P_{E}-V_{E}\right)-d\left(P_{l}-V_{l}-V_{c}\right)}{2 d(k-1)}
$$

$$
\mathrm{Q}_{c}^{c}=\frac{(k-1) c-d k\left(P_{E}-V_{E}\right)+d\left(V_{c}-P_{l}+V_{l}\right)}{2(k-1)}
$$

At this point, the profits of coal-fired power plant is:

$$
\pi_{E}^{\mathrm{C}}=\frac{a c}{2 k}-\frac{a d(a+b)}{2 k(k-1)}-\frac{(k-1)^{2} c^{2}-d^{2}(a+b)^{2}}{4 d(k-1)^{2}}
$$

The profits of coal enterprises are as follows:

$$
\pi_{C}^{\mathrm{C}}=\frac{2 b c d(1-k)-d^{2}\left(a^{2}-b^{2}\right)+c^{2}(k-1)^{2}}{4 d(k-1)^{2}}-\frac{c}{2} V_{C^{-}} \frac{d(a+b)}{2(k-1)} V_{C}
$$

The profits of third party logistics enterprise:

$$
\pi_{L}^{\mathrm{C}}=\frac{\left(P_{l}-V_{l}\right)(k c-c-a d-b d)}{2(k-1)}
$$

Tripartite total profit situation is:

$$
\begin{gathered}
\pi_{T}^{\mathrm{c}}=\frac{2 b c d(1-k)-2 d^{2}\left(a^{2}+a b\right)}{4 d(k-1)^{2}}+\frac{a c}{2 k}-\frac{a d(a+b)}{2 k(k-1)}-\frac{c}{2} V_{C}^{-} \frac{d(a+b)}{2(k-1)} V_{C}+\frac{\left(P_{l}-V_{l}\right)(k c-c-a d-b d)}{2(k-1)} \\
\mathrm{a}=\mathrm{k}\left(P_{E}-\mathrm{V}_{E}\right) ; \mathrm{b}=-\mathrm{V}_{C}+P_{l}-V_{l}
\end{gathered}
$$

With the increase of $P_{E}$ and the decrease of $\mathrm{V}_{E}$, the value of a will increase, which will result in the growth of $\pi_{E}^{\mathrm{C}}$, that is the profits of cooperative coal-fired power plant will increase. At the same time, with the decrease of $V_{c}$, b will increase, and the increase of $\mathrm{b}$ will also lead to the increase of $\pi_{E}^{\mathrm{C}}$, so the profits of cooperative coal-fired power plant will also increase. This shows that when the coal-fired power plants and coal enterprises work together, the profits of coal-fired power plants are affected by two factors. Firstly, the price itself, other variable costs. The second is the variable cost of coal enterprises.

With other variables unchanged, with the increase of $P_{E}$ and the decrease of $\mathrm{V}_{E}$, the value of a will increase, resulting in the increase of $b$. The increase of $b$ leads to the decrease of $\pi_{C}^{C}$. That is under the cooperation between coal-fired power plant and coal enterprises, the profit of coal enterprises will decrease with the increase of $P_{E}$ and the decrease of $V_{E}$. This is due to the limited total profit margin obtained by the cooperation between the coal-fired power plants and coal enterprises. Therefore, with the increase of $P_{E}$ and the decrease of $V_{E}$, the profits of coal-fired power plant should be raised, which will result in the decrease of profit of coal enterprises. It also can be 
seen from the formula that the decrease of $V_{c}$ can promote the decrease of $\pi_{C}^{\mathrm{C}}$. However, as the $V_{c}$ decreases, the increase of $\mathrm{b}$ value will decrease $\pi_{C}^{\mathrm{C}}$. Therefore, even if the variable costs of coal enterprises decrease, their profits have both positive and negative effects. This is due to the profit growth caused by the reduction of costs after the cooperation between coal enterprises and coal-fired power plant, which is partly caused by the coal-fired power plant.

At the same time, in the case of other variables certain circumstances. As $P_{E}$ increases and $V_{E}$ decreases, $\pi_{T}^{c}$ decreases. In the case of cooperation between coal-fired power plants and coal enterprises, the profits of the third-party logistics enterprises will decrease as the price of electricity increases and the cost of power generation decreases.

Finally, as $P_{E}$ increases and $V_{E}$ decreases, the a value will increase, resulting in $\pi_{T}^{c}$ growth. At the same time, the reduction of $V_{c}$ directly aroused the growth of total profit after the cooperation between coal enterprise and coal-fired power plant. Or indirectly through the $b$ value of the growth of cooperative profits. This phenomenon shows that when electricity companies and coal companies cooperate in the supply chain, both the electricity price increase, the reduction of other costs of electricity enterprises and the reduction of the cost of coal enterprises will increase the cooperation profits ${ }^{[13]}$.

\section{NON - COLLABORATIVE GAME ANALYSIS OF THERMAL COAL SUPPLY ENTERPRISES}

Firstly, essay discusses the situation of oversupply. Coal sales in this situation is poor, and coal-fired power plants are more powerful. Coal-fired power plant s will be the first to take action. Electricity companies choose the price $P_{c}$ in order to maximize their profits. In the case of the price of $P_{c}$, coal companies choose the sales volume of coal $\mathcal{Q}_{C}$. Using Stackelberg two-stage dynamic game theory, the first-order optimization condition and Nash equilibrium solution of the second stage coal enterprise are first solved by means of backtracking induction.

In the case of coal price is $P_{c}$, the profits of coal enterprises is maximized, the coal sales volume is:

$$
\mathcal{Q}_{C}^{*}=\frac{c-d V_{C}}{2}
$$

It can be seen that when the profits of coal enterprises are maximized, the coal sales volume is not related to the $P_{c}$.

When the coal-fired power plant profits to maximize, the value of $P_{c}$ is:

$$
P_{C}^{*}=\frac{c}{2 d}+\frac{1}{2}\left(P_{E}-V_{R}\right)
$$

$$
\pi_{E}=\frac{d k}{4}\left[\left(P_{E}-V_{E^{-}} \frac{c}{d}\right)\right]\left(\frac{c}{d}-V_{C}\right)
$$

The profit function of coal enterprise Nash equilibrium is:

$$
\pi_{C}=\frac{1}{4}\left[\frac{C^{2}}{d}+\left(P_{E}-V_{E}-2 V_{C}\right)\left(\mathrm{c}-\mathrm{d} V_{C}\right)-\mathrm{c} V_{C}\right]
$$

The total profits of coal-fired power plants and coal enterprises are:

$\pi_{T}=\frac{C^{2}}{d}(1-k)+\left[(k+1)\left(P_{E}-V_{E}\right)-2 V_{C}\right]\left(c-d V_{C}\right)-c V_{C}(1-k)$

As can be seen from the Nash equilibrium function of coalfired power plant, the profit of coal-fired power plant increases with the increase of $P_{E}$, and it still increases with the decrease of $V_{E}$. At the same time, when the profits of coal-fired power plants $V_{c}$ increase, the unit cost of coal enterprises decrease. This is due to $V_{c}$ declines. Coal prices have scope for decline to promote the profits of coal-fired power plants.

From the Nash equilibrium function of coal enterprises, it is found that the profits of coal enterprises increase with the increase of the sales price $P_{E}$, and the profits of coal enterprises increase with the decrease of $P_{E}$. The increase of profit margins of coal-fired power plant has nothing to do with the increase of $P_{E}$ and the decrease of $V_{E}$. So that coal-fired power plant are willing to pay a higher price to buy coal, which led to the rise in profits of coal enterprises. In addition, with the reduction of unit cost $V_{c}$ of coal enterprise, the profits of coal enterprises will also rise.

From the total profit function can be seen that the sum of profits of coal-fired power plants and coal enterprises are still positively correlated with $P_{E}$, and negatively correlated with $V_{E}$ and $V_{c}$.

When the electricity supply is less than demand, the coalfired plant will have a greater demand for coal. Coal enterprises has strong position in the market, it possesses the initiative. Electricity companies have disadvantage and it only can make decisions after the coal enterprise. According to the national policy, it is assumed that coal enterprises can not arbitrarily raise prices and only make decisions on their sales volume. Electricity companies make decisions on the price of coal. This article continues to use the inverse regression inductive method to analyze, and getting the Nash equilibrium coal sales price $P_{c}$ and coal sales $\mathcal{Q}_{C}$ respectively is:

$$
P_{C}^{*}=\frac{c+d\left(P_{E}-V_{E}\right)}{2 d}
$$

The profits are: 


$$
\mathcal{Q}_{C}^{*}=\frac{c}{2}-\frac{d}{2} V_{c}
$$

The result of the above two formulas is same as that when the electricity supply exceeds the demand. It shows that the Nash Equilibrium results are the same for both of the first decision taken by coal-fired power plant or the coal industry when who is in a strong position. In any case, the main basis for decision-making is the coal's demand function and the firm's profit function. As long as the demand function is consistent with the profit function, no matter which firm makes the first decision, it has no effect on the equilibrium result ${ }^{[14]}$.

\section{RESEARCH ON QuANTUM Game OF THERMAL COAL SUPPLY NETWORK}

Coal supply network is composed by a number of comprehensive evaluation of coal mines, logistics companies, coal-fired plants. After the coal supply and distribution network was established, all sides cooperated and started the game in terms of production, supply and information exchange. In the traditional Hawk Dove Game, both sides have their own hawk tactics and dove tactics. Hawk tactics represent aggression, while Dove tactics represent peaceful cooperative behavior. There exists the phenomenon of uncertainty in measurement, state fluctuation and non-clonality in the distribution networks of thermal coal supply. Based on this, a quantum game model of coal supply network is established and calculated. This part focus on study the mutual game between enterprises of all sides in the thermal coal supply network in order to find out the best operation strategy, and analyze the strategies and benefits of both sides in the Hawk Dove Game in two situations. The first case is that one side of the game adopts the traditional strategy, while the other side adopts the quantum strategy. The second case is that both employ quantum strategies.

\section{A. Unilateral Use of Quantum Game Strategy}

Firstly, this essay analyzes the situation when one side uses a traditional strategy, while another side uses quantum strategy. According to J. Eisert's research, the initial state of the system is assumed to be the complement operator $J \mid 00>$ J is known to both sides. Setting the initial state of the system is a method of quantizing the natural game process. It does not mean that the quantum game can only study the initial state of the J $\mid 00>$ J situation. Under the initial state of this system, both Alice and Bob's initial state is a dove tactic. During the game, the dove strategist keeps his status unchanged while the Hawk strategy represents his own status change. Therefore, setting the initial state of the system does not affect the final result analysis.

In this case, let the game companies be Alice and Bob. Alice is a game player of the traditional strategy user. Bob is a quantum game player. According to Eisert's research, the strategy set by both sides are:

$$
\mathrm{U}(\varphi, \theta)=\left[\begin{array}{cc}
e^{i \varphi} \cos \frac{\theta}{2} & \sin \frac{\theta}{2} \\
-\sin \frac{\theta}{2} & e^{-i \varphi} \cos \frac{\theta}{2}
\end{array}\right], 0 \leq \theta \leq \pi, 0 \leq \varphi \leq \frac{\pi}{2}(19)
$$

Therefore, Alice's strategy is $\mathrm{U}(\varphi, 0)$, when $\varphi=0$ is dove strategy, $\mathrm{U}_{A}=\left(\begin{array}{ll}1 & 0 \\ 0 & 1\end{array}\right)$. when $\varphi=\pi$ is hawk strategy $\mathrm{U}_{A}=\left(\begin{array}{cc}0 & 1 \\ -1 & 0\end{array}\right)$.

Bob's strategy is quantum $U_{B}=U(\varphi, 0)$. Because one side uses a quantum strategy and another side adopts a traditional strategy, so the quantum entanglement between two sides is 0 .

Due to the initial state $\left|\Psi_{0} \geq J\right| 00>$ of the system, $J=\exp \left\{\frac{i r H \otimes H}{2}\right\}$ is taken ${ }^{[15]}$. $\mathrm{r}$ is a measure of the entanglement of the two sides in the game $0 \leq \mathrm{r} \leq \frac{\pi}{2}$.

When Alice uses a dove strategy, there will be different game outcomes:

Given the degree of entanglement $r=0, J=\exp \left\{\frac{o i H \otimes H}{2}\right\}$, then $/|00 \geq| 00>$

System final state $\psi=J^{\dagger}(U(\theta, \varphi), D) J\left|00 \geq \cos \frac{\theta}{2}\right| 00>-\sin \frac{\theta}{2} \mid 10>$, Given Alice adopts a dove strategy, the game system is in a superposition of the $\mid 00>$ state with $\cos ^{2} \frac{6}{2}$ probability and the $\mid 10>$ state with $\sin ^{2} \frac{\theta}{2}$ probability.

In this case, the profit function of Alice and Bob is calculated as follows:

Alice's earnings

$$
S_{A}=4 \cos ^{2} \frac{\theta}{2}+\sin ^{2} \frac{\theta}{2}=4-3 \sin ^{2} \frac{\theta}{2} \geq S_{A}(D, H)
$$

Bob’s earnings

$$
S_{B}=4 \cos ^{2} \frac{\theta}{2}+6 \sin ^{2} \frac{\theta}{2}=4+2 \sin ^{2} \frac{\theta}{2} \leq S_{B}(D, H)
$$

If Alice is given a hawk strategy, then the revenue functions of Alice and Bob are:

Alice's revenue function is

$$
S_{A}=6 \cos ^{2} \frac{\theta}{2}+0 \sin ^{2} \frac{\theta}{2} \leq S_{A}(H, D)
$$

Bob's revenue function is

$$
S_{B}=1 \cos ^{2} \frac{\theta}{2}+0 \sin ^{2} \frac{\theta}{2} \geq S_{B}(H, D)
$$

If the quantum entanglement between the two sides are 0 , the decision-making process of both sides have no relationship. If one adopts the quantum game and the other adopts the traditional strategy, its equilibrium result will not surpass the traditional model of Hawk Dove Game.

However, we should see the advantages of using quantum games. Based on the above analysis results, we can see that 
when Alice adopts the hawk strategy, if Bob adopts the quantum game method, then Bob's return will be higher than using the traditional game. This shows that in the game of thermal coal supply network, if the opponent is strong and aggressive. The weak side can adopt quantum strategies to reduce their losses.

\section{B. Both Use Quantum Game Strategy}

When both sides adopt the quantum strategy, Alice and Bob's game strategies are as follows:

$$
\begin{aligned}
& \mathrm{U}_{A}\left(\varphi_{1}, \theta_{1}\right)=\left[\begin{array}{cc}
e^{i \varphi_{1}} \cos \frac{\theta_{1}}{2} & \sin \frac{\theta_{1}}{2} \\
-\sin \frac{\theta_{1}}{2} & e^{-i \varphi_{1}} \cos \frac{\theta_{1}}{2}
\end{array}\right], \\
& \mathrm{U}_{B}\left(\varphi_{2}, \theta_{2}\right)=\left[\begin{array}{cc}
e^{i \varphi_{2}} \cos \frac{\theta_{2}}{2} & \sin \frac{\theta_{2}}{2} \\
-\sin \frac{\theta_{2}}{2} & e^{-i \varphi_{2}} \cos \frac{\theta_{2}}{2}
\end{array}\right]
\end{aligned}
$$

The final form of the game:

$e^{i \varphi_{1}} \cos \cos \frac{\theta_{1}}{2} e^{i \varphi_{2}} \cos \frac{\theta_{2}}{2}\left|00>-e^{-i \varphi_{1}} \cos \frac{\theta_{1}}{2} \sin \frac{\theta_{2}}{2}\right| 01>-\sin \frac{\theta_{1}}{2} \cos \frac{\theta_{2}}{2}\left|10>-\sin \frac{\theta_{1}}{2} \sin \frac{\theta_{2}}{2}\right| 11>$

If both sides have the largest degree of entanglement, when $\theta_{1}=\theta_{2}$, the revenue functions of Alice and Bob both are: $S=4 \cos ^{2} \frac{\theta}{2}+3 \cos ^{2} \frac{\theta}{2} \sin ^{2} \frac{\theta}{2}$, when $\theta=0 S=4$.

The revenue of both sides is $(4,4)$. When both sides adopt the quantum strategy, Alice and Bob's total revenue is greater than or equal to the total revenue in the traditional way.

\section{The Explanation of Quantum Game Results}

\section{- Quantum strategy explanation}

Usually, Enterprises do not have the absolute "Hawk strategy" or the absolute "Dove strategy" when they implement Hawk Dove Game with other market players. Aggression and defensive attitudes among enterprises are mixed. On the one hand, this mixture strategy is expressed in terms of range. For example, when an enterprise takes an aggressive attitude toward certain issues in the Hawk Dove Game, it can take a cooperative attitude toward other issues. On the other hand, this mixture strategy is expressed in terms of degree. The demands made by an enterprise on an adversary are not total aggression or total defense. This shows the limitation when it comes to studying the Hawk Dove Game among enterprises in a complex supply network. Therefore, the quantum game strategy represents a mixed strategy of aggression or cooperation.

- The explanation of the game proceeds

From the analysis of this paper, we can see that if the internal enterprises of the thermal coal supply network adopt the quantum strategy in their decision-making, there are two benefits:

If the strong side attack the weak side, the weak side can reduce their losses by using quantum strategy.

When both sides adopt quantum strategy, that means both sides use hybrid strategy of aggression and cooperation. Both sides will achieve greater benefits than a single strategy.

\section{SUMMARY}

In this paper, collaborative game research, non-cooperative game research and quantum game research are carried out for the coal mine enterprises, transport enterprises and coal-fired power plant in the coal supply chain. And makes corresponding tactics analysis to the cooperative transaction under different determinants and selection variables. In order to build a dynamic coal supply network and collaborative optimization strategy, construction strategy of thermal coal supply network alliance and optimal support strategy of thermal coal supply network, it further provides the operational guarantee of the cooperative operation mechanism of thermal coal supply network.

\section{REFERENCES}

[1] Z. Younes, M. Ilic, "Generation Strategies for Gaming Transmission Constraints Will the Deregulated Electric Power Market $\mathrm{Be}$ an Oligopoly?” Hawaii International Conference on System Sciences. IEEE, 1998:112-121 vol.3.

[2] R.W. Ferrero, J.F. Rivera, S. M. Shahidehpour, "Application of games with incomplete information for pricing electricity in deregulated power pools,” IEEE Transactions on Power Systems, 2002, 13(1):184-189.

[3] R. Green, "Competition in Generation: the Economic Foundations," Proceedings of the IEEE, 2000, 88(2): 128-139.

[4] F. Han, W. Tao, Y. Lv, "The Application of Game Theory in Bidding Strategy of Generation Companies,” Journal of Taiyuan University of Technology, 2004, 35 (1): 61-63.

[5] Z. Yuan, C. Jiang, Z. Hou, "Nash equilibrium analysis of bidding strategies of power suppliers under different settlement methods," Journal of Shanghai Jiaotong University, 2004,38 (8): 36-41.

[6] Y. Zhang, X. Luo, J. Xue, "Improvement of output of power plant in power market under incomplete information Cournot model," Proceeding of the CSEE, 2003, 23 (6): 23-28.

[7] J. Liao, "Game Theory in Power Market and Implementation of Decision Support System,” Wuhan: Huazhong University of Science and Technology .2006: 36-37.

[8] National Bureau of Statistics, China Statistical Yearbook, Beijing: China Statistics Press, $2011 \sim 2015$.

[9] J. Miao, "Railway transport to the coal “tilt,”” Newsweek, 2008 (24): 41.

[10] L. YU, F. Jin, B. Zhang, "Research on the Present Situation, Development Trend and Countermeasures of China Coal Transportation,” Railway Economic Research, 2006, (5): 38-41. DOI: 10.3969 / issn.1004-9746.2006.05.013.

[11] P. Wang, "Analysis of the Necessity of Construction of Coal Transfer Base,” Integrated Transportation. 2010 (05): 46-52.

[12] B. Liu, "Chinese vertical relationship between coal and electricity industry: determinants and model choices," Beijing: Economic Management Publishing, 2010: 87.

[13] F. Wang, Z. Yu, "Study on the Stability of Symbiotic System in Coalfired Power Industry Based on Logistic Model,” Acta Ecologica Sinica, 2015,35 (23): 7912-7920. 
[14] D. Wang, R. Nie, Y. Liu, "Study on the Impact of Linkages between China's Coal and Electricity Based on Complex Network Model," Systems Engineering, 2016 (08): 011

[15] X. Zhang, "2015 Coal Industry Situation Analysis and Future Development Judgment," Coal Economic Research, 2016 (1): 11-14. 